\title{
Revealing the catalytic mechanism of an ionic liquid with an isotope exchange method
}

\author{
Sun Xuewen* and Zhao Suoqi \\ State Key Laboratory of Heavy Oil Processing, China University of Petroleum, Beijing 102249, China \\ (C) China University of Petroleum (Beijing) and Springer-Verlag Berlin Heidelberg 2011
}

\begin{abstract}
The alkylation mechanism catalyzed by an ionic liquid (as a Lewis acid) may be different from the traditional alkylation mechanism catalyzed by Brønsted acid, especially as their initiation steps are still not clear. In this paper, an isotope exchange method is used to investigate the catalytic mechanism of $\mathrm{AlCl}_{3} /$ butyl-methyl-imidazolium chloride ionic liquid in the alkylation of benzene with 1-dodecene. The proposed catalytic mechanism was confirmed by analysis of ionic liquid before and after reaction and of the alkylation products of deuterated benzene $\left(\mathrm{C}_{6} \mathrm{D}_{6}\right)$ with 1-dodecene. The proposed mechanism consists of the equilibrium reaction between $\left[\mathrm{Al}_{2} \mathrm{Cl}_{7}\right]^{-}+\mathrm{H}^{+}$and $\left[\mathrm{AlHCl}_{3}\right]^{+}+\left[\mathrm{AlCl}_{4}\right]^{-}$, in which the Brønsted acid $\left[\mathrm{AlHCl}_{3}\right]^{+}$is supplied by the reaction of $2-\mathrm{H}$ on the imidazolium ring and $\left[\mathrm{Al}_{2} \mathrm{Cl}_{7}\right]^{-}$. The alkylation reaction is initiated by the Brønsted acid $\left[\mathrm{AlHCl}_{3}\right]^{+}$which reacts with 1-dodecene to form a carbonium ion, then the carbonium ion reacts with benzene to form an unstable $\sigma$ complex, leading to the formation of 2-phenyldodecane.
\end{abstract}

Key words: Catalytic mechanism, ionic liquid, isotope exchange method, alkylation, deuterated benzene

\section{Introduction}

The use of ionic liquids (IL) as an alternative to conventional hazardous solvents has received very considerable attention for its applications in electrochemistry (Hussey, 1988; Wilkes et al, 1982), liquid/liquid separations (Swatloski et al, 2002b; Blanchard et al, 1999), extractions (Huddleston et al, 1998), catalysis (Swatloski et al, 2002a; Cole et al, 2002; Zhao et al, 2002), biocatalysis (Cull et al, 2000; Sheldon et al, 2002), and polymerization (Hardacre et al, 2002b; Carmichael et al, 2000). Ionic liquids are benign and stable solvents for a wide range of organic and inorganic materials (Nara et al, 2001; Green et al, 2000). The advantages of ionic liquids include negligible vapor pressure, potential for recycling, compatibility with various organic compounds and organometallic catalysts, and ease in separation of reaction products (Welton, 1999). Ionic liquids with strong acidity can be used as acid catalysts for alkylation processes. In addition, the physical and chemical properties of an ionic liquid can be adjusted by varying its organic cation and inorganic anion. The organic cation controls the solubility, density and viscosity of the ionic liquids. The properties of the liquid ion vary significantly with various alkyl groups used as cations. The acidity of the ionic liquid depends on the metal halide used and the ratio of metal halide to organic base (Welton, 1999; Seddon, 1997). Hence, to gain insights into ionic-liquid-catalyzed alkylation

* Corresponding author. Email: sunxwb2000@cup.edu.cn Received March 14, 2011 reaction processes, it is necessary to understand the catalytic mechanism of ionic liquids.

Alkylation of benzene with linear $\mathrm{C}_{10}-\mathrm{C}_{14}$ olefins is an established industrial process. The linear alkylbenzene (LAB) products are used as intermediates in the production of surfactants and detergents. At present, the acid catalysts used in the commercial alkylation process are hydrofluoric (HF) acid and sulfuric acid $\left(\mathrm{H}_{2} \mathrm{SO}_{4}\right)$, which are corrosive and hazardous substances. Attempts have been made to use $\mathrm{AlCl}_{3}$ IL as catalyst for alkylation reactions. It has been shown that $\mathrm{AlCl}_{3}$ IL can lower the alkylation reaction temperature, has a high selectivity to 2-alkylbenzene, and can be separated easily from the alkylate products (Qiao et al, 2004; Decastro et al, 2000; Qiao and Deng, 2001; Xin et al, 2005). Albermale (formerly Akzo-Nobel) developed IL alkylation catalysts with triethylamine hydrochloride and aluminium chloride, which can be economic alternatives to imidazolium-based salts (Hope et al, 2004). These IL's were designed specifically for catalyzed alkylation of benzene with 1-dodecene (Sherif et al, 1998), and had a higher 2-dodecylbenzene yield than the conventional HF catalyst. A large number of investigations have been conducted studying the mechanism of $\mathrm{AlCl}_{3}$ IL catalyzed alkylation (Trulove et al, 1994; Sun and Zhao, 2008; Compell and Johnson, 1995; Schmerling, 1953; Whitmore, 1932; Ma and Johnson, 1995). Smith et al (1989) reported that arene was protonated by butyl-methylimidazolium chloride $([\mathrm{bmim}] \mathrm{Cl})-\mathrm{AlCl}_{3} / \mathrm{HCl}$, indicating that the alkylation was catalyzed by strong Brønsted acid, as shown in the following reaction:

$$
\text { arene }+\mathrm{Al}_{2} \mathrm{Cl}_{7}^{-}+\mathrm{HCl} \rightarrow \text { arene- } \mathrm{H}^{+}+2\left[\mathrm{AlCl}_{4}\right]^{-}
$$


As there was trace water in the reaction system, so $\mathrm{HCl}$ was produced by hydrolysis of ionic liquid. According to this interpretation, if there was no water in the system, the ionic liquid cannot catalyze the alkylation.

It is known that the strong Lewis acid $\left[\mathrm{Al}_{2} \mathrm{Cl}_{6} \mathrm{Br}\right]^{-}$can react with hydrogen atoms at the 2-position of an imidazolium ion to form a Brønsted acid (Arduengo et al, 1991; Gifford and Palmisano, 1987). Yoo et al (2004) examined the alkylation of isobutane with 2-butene using methylimidazolium bromide $([\mathrm{mim}] \mathrm{Br})-\mathrm{AlCl}_{3}$, and postulated that the alkylation reaction was catalyzed by the Brønsted acid $\left[\mathrm{AlHCl}_{3}\right]^{+}$which was formed from the association of $\left[\mathrm{Al}_{2} \mathrm{Cl}_{7}\right]^{-}$ with $\mathrm{H}^{+}$, which is dissociated from 2-H of an imidazolium ring. However, there is no conclusive evidence for it, only an inference. Although the IL catalyzed alkylation reactions have been extensively investigated, the reaction mechanism of the initiation step is still not clear.

In this paper, an isotope substitution method was used to investigate the reaction initiation of IL catalyzed alkylation of deuterated benzene $\left(\mathrm{C}_{6} \mathrm{D}_{6}\right)$ with 1-dodecene using [bmim]Cl$\mathrm{AlCl}_{3}$ catalyst. The reaction mechanism was determined by tracking the path of the deuterium atom during the reaction process.

\section{Experimental}

\subsection{Materials}

Deuterated benzene $\left(\mathrm{C}_{6} \mathrm{D}_{6}, 99.6 \%\right.$ purity $)$ was obtained from Sigma-Aldrich Corporation (USA), 1-dodecene (99.9\% purity) and anhydrous $\mathrm{AlCl}_{3}$ were from Beijing Chemical Regent Company, China.

\subsection{Preparation of ionic liquid}

Butyl-methyl-imidazolium chloride ([bmim]Cl) was prepared the reaction of dried and redistilled $\mathrm{N}$-methylimidazolium with a slight molar excess of 1-chlorobutane in a stainless-steel autoclave (Munson et al, 2002). The autoclave was sealed and pressurized with nitrogen to 0.51 $\mathrm{MPa}$. It was then heated to $90^{\circ} \mathrm{C}$ for $18 \mathrm{~h}$. After the reaction, the autoclave was cooled to room temperature. The material in the autoclave was transferred to a rotary evaporator, in which the unreacted chloro-butane and 1-methylimidazole were removed by nitrogen stripping at $95{ }^{\circ} \mathrm{C}$ for 18 hours. The reaction product was washed with acetonitrile. The washed product composed of [bmim] $\mathrm{Cl}$ was vacuum-dried at $105^{\circ} \mathrm{C}$ to remove the residual solvent and water.

The $[\mathrm{bmim}] \mathrm{Cl} /\left[\mathrm{AlCl}_{3}\right]$ ionic liquid was prepared by adding anhydrous $\mathrm{AlCl}_{3}$ to $[\mathrm{bmim}] \mathrm{Cl}$ in a $2: 1$ molar ratio. The reaction mixture was continuously stirred for $12 \mathrm{~h}$ at room temperature. The entire process was carried out in a glove box under a nitrogen atmosphere to avoid hydrolysis of $\mathrm{AlCl}_{3}$. The resulting $[\mathrm{bmim}] \mathrm{Cl} /\left[\mathrm{AlCl}_{3}\right]$ ionic liquid was stored in a dry inert atmosphere. Before use, the $[\mathrm{bmim}] \mathrm{Cl} /\left[\mathrm{AlCl}_{3}\right]$ ionic liquid was dried with $3 \mathrm{~A}$ molecular sieves to keep the moisture content below $10 \mu \mathrm{g} / \mathrm{g}$.

\subsection{Alkylation of benzene with 1-dodecene}

A $200 \mathrm{~mL}$ autoclave reactor was equipped with two glass windows, a gas inlet valve, a sample exit line, a magnetic stirrer, and a piston for controlling the reactor pressure. The autoclave was put in a temperature-programmed oven. Prior to the experiment, the autoclave was purged with nitrogen and then evacuated. The $[\mathrm{bmim}] \mathrm{Cl} /\left[\mathrm{AlCl}_{3}\right]$ ionic liquid $(25$ $\mathrm{mL}$ ) was put into the reactor and then heated to $30^{\circ} \mathrm{C}$. Then, $150 \mathrm{~mL}$ of dodecene- $\mathrm{C}_{6} \mathrm{D}_{6}$ mixture (molar ratio 1:10) was charged into the reactor using a plunger pump at $500 \mathrm{~mL} / \mathrm{h}$. The alkylation reaction was carried out for $10 \mathrm{~min}$ while the mixture was stirred at $650 \mathrm{rpm}$. Subsequently, the reaction product and catalyst were decanted from the reactor and let stand for $15 \mathrm{~min}$. Then the reaction product and catalyst were transferred to a separation funnel, in which the reaction product and catalyst were separated into upper and lower phases, respectively. The reaction product and catalyst were collected for analysis.

\subsection{Analysis method}

The reaction product was examined by gas chromatography (GC) analysis. A temperature programmed GC (SP-3420, Beijing Beifen Analysis Equipment Technology Co., Ltd, China) was equipped with a flame ionization detector (FID) and an OV-101 capillary column $(0.32 \mathrm{~mm}$ in diameter $\times 50 \mathrm{~m}$ in length). The temperature of the $\mathrm{GC}$ was raised from $50^{\circ} \mathrm{C}$ to $250^{\circ} \mathrm{C}$ at $10^{\circ} \mathrm{C} / \mathrm{min}$, and then maintained at $250^{\circ} \mathrm{C}$ for $20 \mathrm{~min}$.

Qualitative analysis of the product was carried out in a SSQ710V GC mass spectroscope (MS) (Aglient company, USA). Samples were separated using a HP-5MS capillary column. The initial column temperature was set at $80{ }^{\circ} \mathrm{C}$ and kept at $80{ }^{\circ} \mathrm{C}$ for $1 \mathrm{~min}$ and then increased to $300{ }^{\circ} \mathrm{C}$ at 10 ${ }^{\circ} \mathrm{C} / \mathrm{min}$ and kept at $300{ }^{\circ} \mathrm{C}$ for $10 \mathrm{~min}$. The sample injection temperature was $290{ }^{\circ} \mathrm{C}$ and the temperature in the sample transmission line was $250{ }^{\circ} \mathrm{C}$. The flow rate of helium carrier gas was $60 \mathrm{~mL} / \mathrm{min}$ at $0.11 \mathrm{MPa}$. Mass spectra were collected over the mass range of 35-350 amu at 1 scan per second at 70 ev energy ionization.

All the NMR spectra were recorded on a JEOL JNM ECA-600. The resonant frequencies for distortionless enhancement by polarization transfer (DEPT) was 150.9134 $\mathrm{MHz}$. Analysis of 2-H intensity in the imidazolium ring of ionic liquid before and after reaction was carried out at $25^{\circ} \mathrm{C}$. The resonant frequencies for 27Al-NMR were $150.9134 \mathrm{MHz}$ and analysis temperature was $80{ }^{\circ} \mathrm{C}$. Spectra were acquired at a sweep-width of $31250.0 \mathrm{~Hz}$. The analysis samples were dissolved in C6D6, with a concentration of $0.5 \mathrm{wt} \%$. $_{3} \mathrm{Al}$ was used as a reference.

A ZDJ-3S Karl-Fischer (Beijing Xianquweifeng Company, China) was used to determine the trace content of water in the $[\mathrm{bmim}] \mathrm{Cl} /\left[\mathrm{AlCl}_{3}\right]$ ionic liquid catalyst.

\section{Results and discussion}

\subsection{Catalytic function of water-free ionic liquid}

In the conventional $\mathrm{HF}$ or $\mathrm{H}_{2} \mathrm{SO}_{4}$ catalyzed alkylation processes, the acid catalyst function of $\mathrm{HF}$ and $\mathrm{H}_{2} \mathrm{SO}_{4}$ is Brønsted acid. The Brønsted acid provides $\mathrm{H}^{+}$directly which acts as an initiator to catalyze the alkylation reaction via the 
carbocation mechanism. However, the ionic liquid is a Lewis acid which cannot provide $\mathrm{H}^{+}$directly. Generally, ionic liquid catalyzed alkylation reactions were considered to be initiated by solvated $\mathrm{H}^{+}$, which is dissociated from $\mathrm{HCl}$ produced by hydrolysis of $\mathrm{AlCl}_{3}$. But the ionic liquid and reactants were dewatered before reaction, so hydrolysis of $\mathrm{AlCl}_{3}$ would not occur, and $\mathrm{HCl}$ would not be produced, as a result, nonsolvated $\mathrm{H}^{+}$existed in the system. According to the above interpretation, the alkylation reaction cannot occur. But the actual case was completely different.

The GC spectrum of alkylation products of $\mathrm{C}_{6} \mathrm{D}_{6}$ with 1 -dodecene is shown in Fig. 1. It can be seen that different peaks appear in Fig. 1. These spectrum peaks are assigned as 6-, 5-, 4-, 3-, 2-phenyldodecanes, respectively, with increasing retention time. This indicated that the alkylation reactions can still occur using water-free ionic liquid as catalyst. To better understand the catalytic mechanism of the ionic liquid, it is essential to determine the source of initiator.

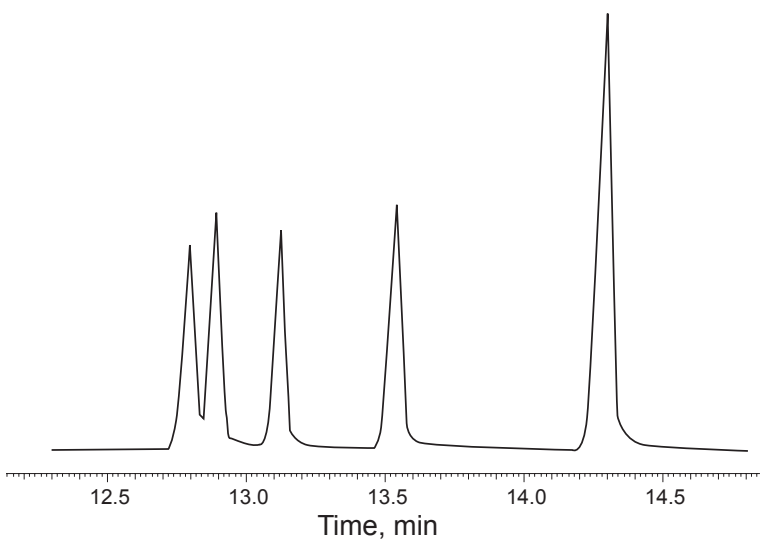

Fig. $1 \mathrm{GC}$ spectrum of alkylate products of $\mathrm{C}_{6} \mathrm{D}_{6}$ with 1-dodecen

\subsection{The acidity of different $H$ in ionic liquid}

There are various possible $\mathrm{H}$ ion sources in the ionic liquid. To determine which acts as the initiator of the alkylation reaction, the [bmim]Cl solution was subjected to anhydrous potassium hydroxide $(\mathrm{KOH})$ alcohol solution titration. Fig. 2 shows the FT-IR spectra of [bmim]Cl before and after $\mathrm{KOH}$ titration. The adsorption band intensity at

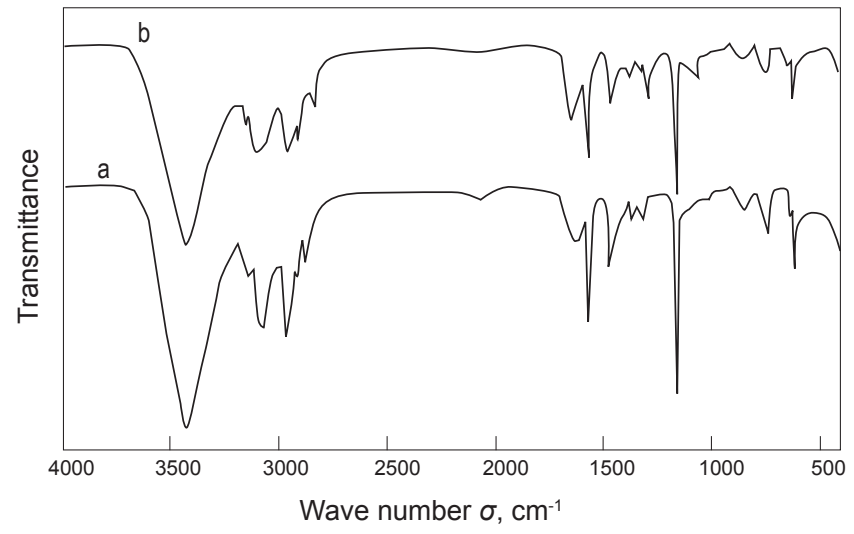

Fig. 2 FT-IR spectra of [bmim] Cl ionic liquid before (a) and after (b) anhydrous $\mathrm{KOH}$ alcohol solution titration.
$1600-1700 \mathrm{~cm}^{-1}$ increased remarkably, indicating the shear deformation vibration of $\mathrm{H}_{2} \mathrm{O}$ ( $\mathrm{Lu}$ and Deng, 1989). This showed that water was formed as a result of reaction of the $\mathrm{H}$ of the ionic liquid with the $\mathrm{OH}^{-}$of $\mathrm{KOH}$ anhydrous solution, indicating the proton acidity of the ionic liquid.

To determine the acidity of the various $\mathrm{H}$ atoms of the ionic liquid, the ${ }^{1} \mathrm{HNMR}$ method was employed to analyze the solution of [bmim] $\mathrm{Cl}$ before and after $\mathrm{KOH}$ titration. The ${ }^{1}$ HNMR spectra in Fig. 3 show that the intensity of 4,5-H chemical shift at $8 \mathrm{ppm}$ on the imidazolium ring was reduced slightly and the $2-\mathrm{H}$ chemical shift at $9.5 \mathrm{ppm}$ disappeared completely after $\mathrm{KOH}$ titration. The intensity of the $\mathrm{H}$ chemical shift at 1.0-2.0 ppm on alkyl chain did not change. This indicates that the $2-\mathrm{H}$ on the imidazolium ring has a significant proton acidity and its acidity is stronger than those of 4,5-H on the imidazolium ring and $\mathrm{H}$ on alkyl chain. This result is consistent with that reported by Arduengo et al (1991).

The effect of the $\mathrm{AlCl}_{3}$ content of the ionic liquid on the $2-\mathrm{H}$ chemical shifts was also investigated, and it was found that the 2-H chemical shifts were shifted downfield with increasing $\mathrm{AlCl}_{3}$ content. This suggests that the $2-\mathrm{H}$ on the imidazolium ring of the ionic liquid can be disengaged easily. So solvated $\mathrm{H}^{+}$or its complex must exist in the system, and act as a Brønsted acid to initiate the alkylation. The results are shown in Fig. 4.
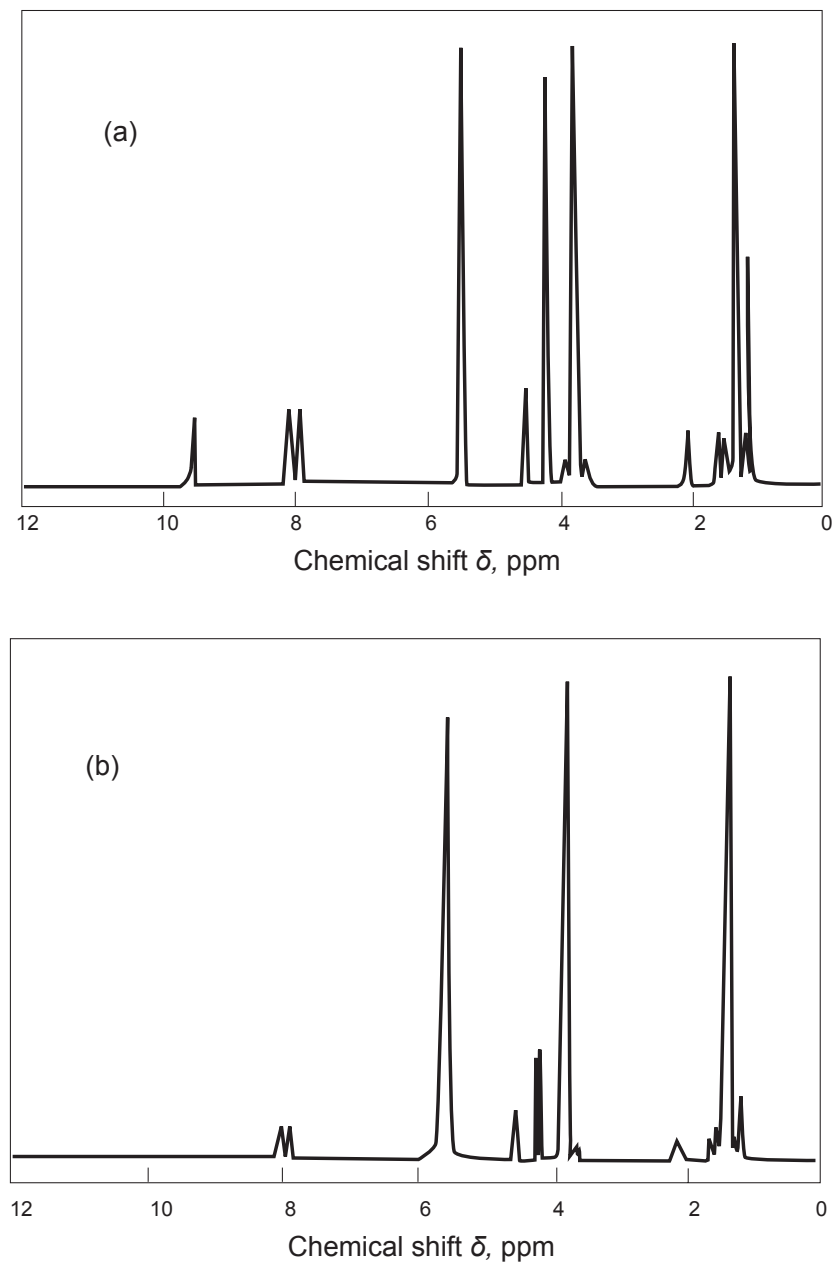

Fig. $3{ }^{1} \mathrm{HNMR}$ spectra of [bmim] $\mathrm{Cl}$ before (a) and after (b) $\mathrm{KOH}$ titration 


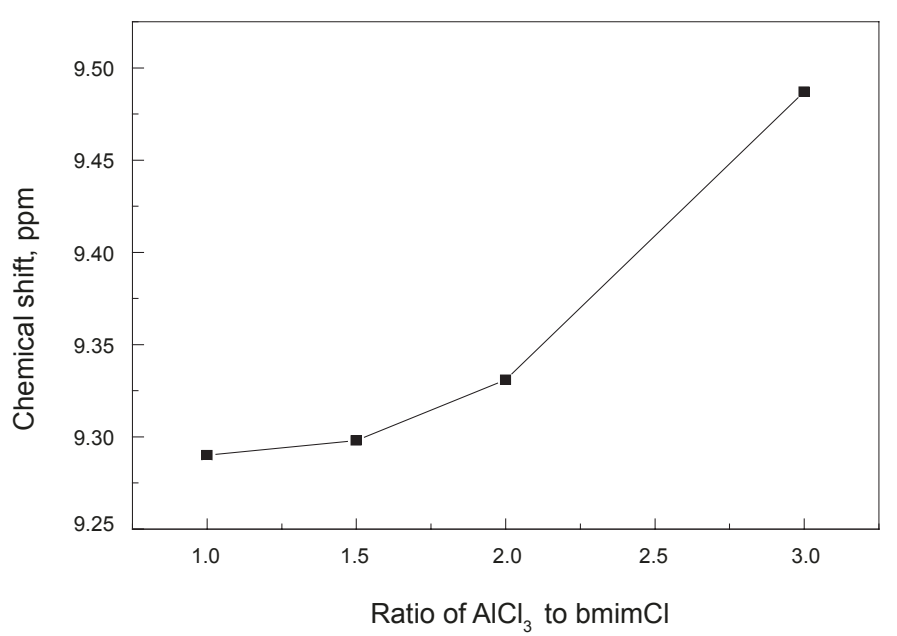

Fig. 4 The effect of $\mathrm{AlCl}_{3}$ content on chemical shift

\subsection{Catalytic mechanism of the ionic liquid}

In order to determine the form of the initiator in the system, the structure of the ionic liquid was analyzed using Al-NMR.

Fig. 5 shows the Al-NMR spectra of ionic liquid before and after alkylation. It can be seen that the increased abundance of $\left[\mathrm{AlCl}_{4}\right]^{-}$was at the expense of $\left[\mathrm{Al}_{2} \mathrm{Cl}_{7}\right]^{-}$after the alkylation reaction. This suggests that $\left[\mathrm{AlCl}_{4}\right]^{-}$and $\left[\mathrm{Al}_{2} \mathrm{Cl}_{7}\right]^{-}$are in equilibrium:

$$
\left[\mathrm{Al}_{2} \mathrm{Cl}_{7}\right]^{-}+\mathrm{H}^{+} \rightleftarrows\left[\mathrm{AlHCl}_{3}\right]^{+}+\left[\mathrm{AlCl}_{4}\right]^{-}
$$

Hence, the form of Brønsted acid is $\left[\mathrm{AlHCl}_{3}\right]^{+}$which acts as an initiator to catalyze the alkylation, and the $\mathrm{H}$ in
$\left[\mathrm{AlHCl}_{3}\right]^{+}$is disengaged from $2-\mathrm{H}$ on the imidazolium ring. The proposed reaction mechanism is shown in Fig. 6.
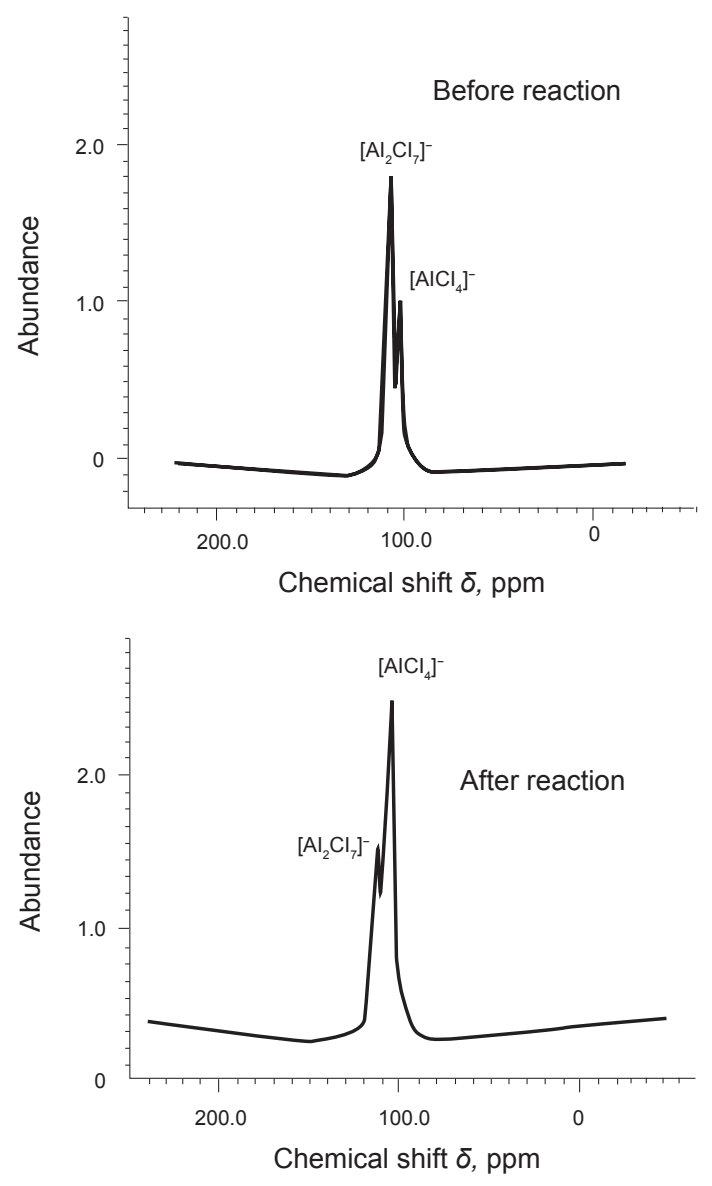

Fig. 5 Structure of ionic liquid before and after alkylation reaction

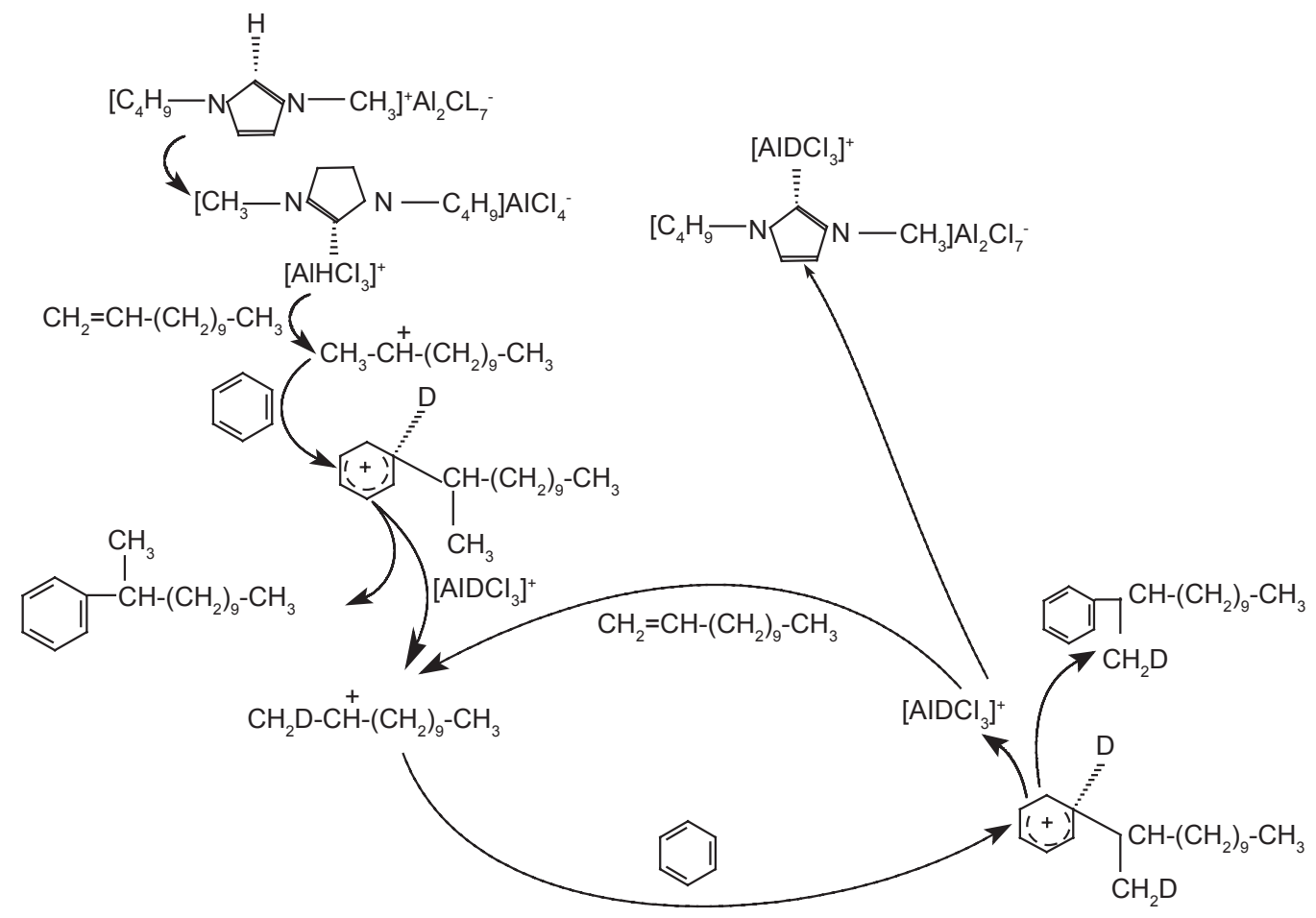

Fig. 6 Catalytic mechanism of Brønsted acid in the alkylation reaction 


\subsection{Examination of the mechanism of alkylation catalyzed by ionic liquid}

According to the above mechanism, the Brønsted acid $\left[\mathrm{AlHCl}_{3}\right]^{+}$reacted first with dodecene to form the carbonium ion, then the carbonium ion further reacted with benzene to generate an unstable $\sigma$ complex, and deuterium $\mathrm{D}^{+}$ion on the ring of the $\sigma$ complex was transferred to $\left[\mathrm{AlHCl}_{3}\right]^{+}$ to replace $\mathrm{H}$ and form $\left[\mathrm{AlDCl}_{3}\right]^{+}$. Since $\mathrm{C}_{6} \mathrm{D}_{6}$ was used as a reactant, if the proposed mechanism is correct, deuterium would appear in the alkyl chain of products. To ascertain the position of deuterium in the alkyl chain, DEPT NMR analysis was conducted. Figs. 7 and 8 are the expanded DEPT NMR spectra at $\delta 11.0-12.4 \mathrm{ppm}$ and $\delta 21.8-22.5 \mathrm{ppm}$, respectively. The negative peaks were split into three peaks, indicating deuterium in the $-\mathrm{CH}_{2}$ group. The three peaks in Fig. 7 were assigned to $-\mathrm{CH}_{2} \mathrm{D}$ of 3- and 6-phenyldodecanes, whereas those in Fig. 8 assigned to $-\mathrm{CH}_{2} \mathrm{D}$ of 2-phenyldodecane. The results showed that deuterium was at the first carbon of the dodecylbenzene isomers.

To examine the proposed catalytic mechanism of the ionic liquid catalyst in the alkylation reaction, GC-MS analysis of various reaction products were performed. Figs. 9 and 10 show the MS spectra of 2-phenyldodecanes and 3 -phenyldodecanes, respectively. The two molecular ion peaks of 2-alkyl-dodecane appeared at $\mathrm{m} / \mathrm{z} 251$ and 252 . The relative abundance of 2-alkyl-dodecane with $\mathrm{m} / \mathrm{z} 251$ was
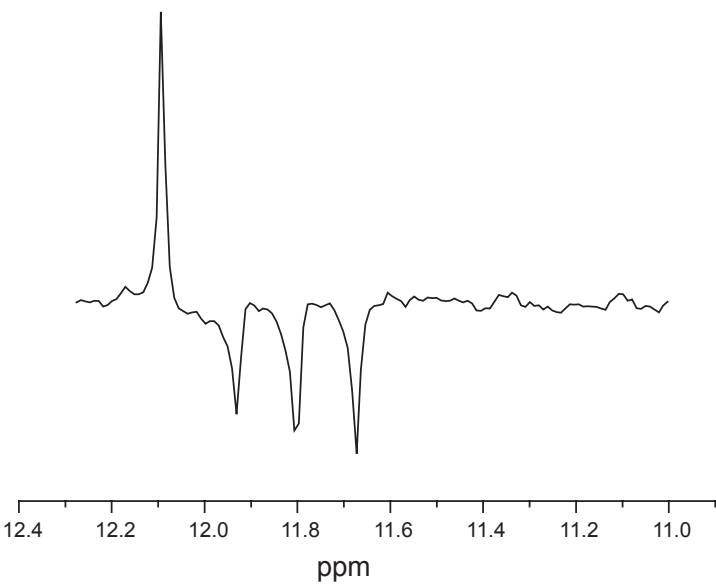

Fig. 7 Enlarged DEPT NMR spectrum at $\delta 11.0$ to $12.4 \mathrm{ppm}$

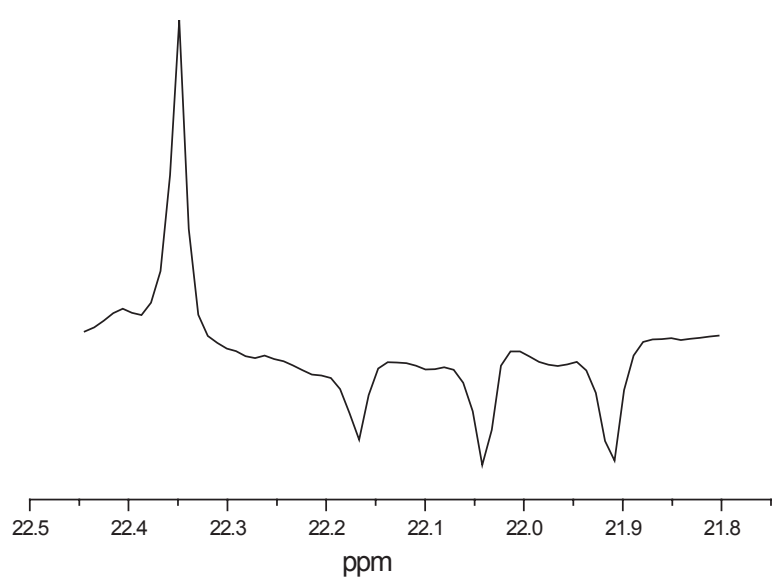

Fig. 8 Enlarged DEPT NMR spectrum at $\delta 21.8$ to $22.5 \mathrm{ppm}$

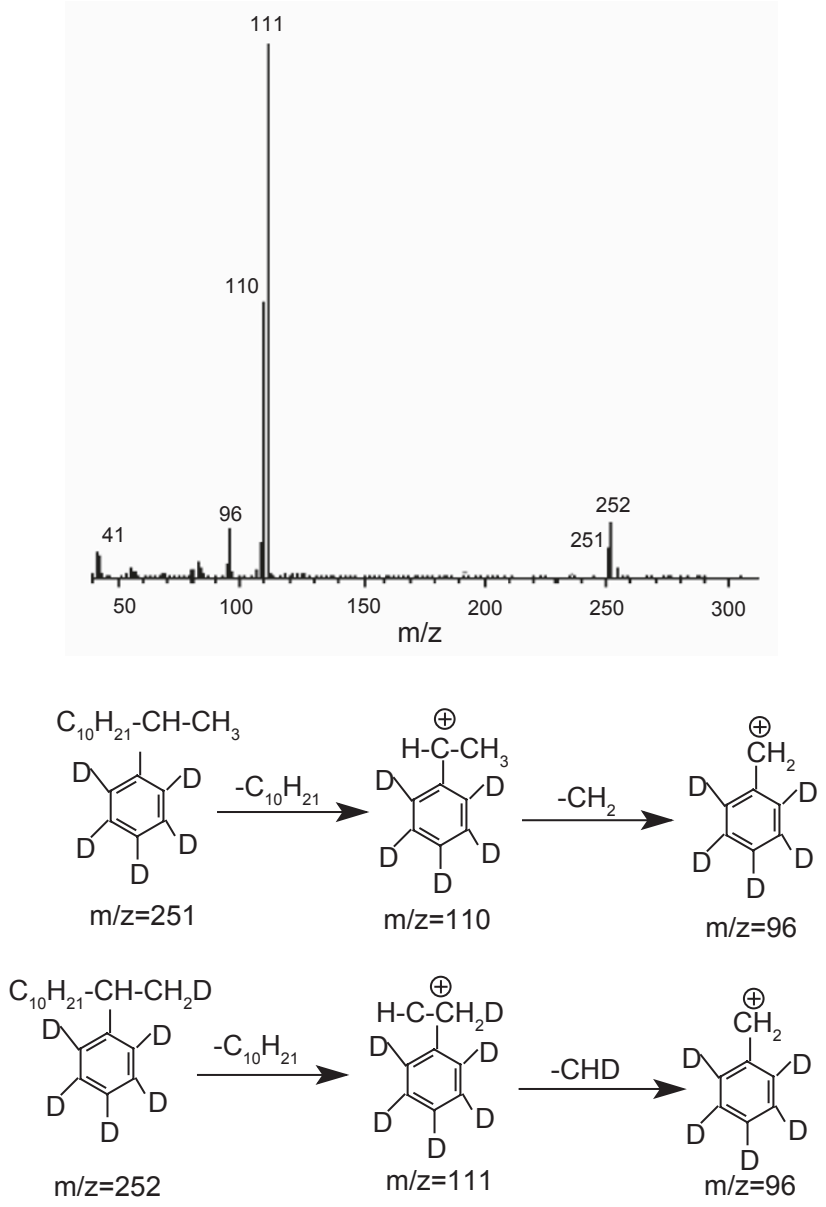

Fig. 9 Mass spectrum of 2-alkyl-dodecane

lower than that with $\mathrm{m} / \mathrm{z} 252$. This suggests that the 2-alkyldodecanes at $\mathrm{m} / \mathrm{z} 251$ and 252 are isomers: $\mathrm{C}_{6} \mathrm{D}_{5}-\mathrm{C}_{12} \mathrm{H}_{25}$ and $\mathrm{C}_{6} \mathrm{D}_{5}-\mathrm{C}_{12} \mathrm{H}_{24} \mathrm{D}$, respectively.

The spectrum peaks at $\mathrm{m} / \mathrm{z} 110$ and 111 in Fig. 9 are phenylethyl carbonium ions $\mathrm{C}_{6} \mathrm{D}_{5}-\mathrm{C}_{2} \mathrm{H}_{4}{ }^{+}$and $\mathrm{C}_{6} \mathrm{D}_{5}-\mathrm{C}_{2} \mathrm{H}_{3} \mathrm{D}^{+}$, respectively, which are cleavages of $-\mathrm{C}_{10} \mathrm{H}_{21}{ }^{+}$from the molecular ion. Further cleavage of the phenylethyl ion and $-\mathrm{CH}_{2}{ }^{+}$and $-\mathrm{CHD}^{+}$resulted in a benzyl carbonium ion of $\mathrm{m} / \mathrm{z}$ $96\left(\mathrm{C}_{6} \mathrm{D}_{5}-\mathrm{CH}_{2}{ }^{+}\right)$. The MS analysis showed that the 2-alkyldodecane was a part of a linear alkyl chain with a $-\mathrm{CH}_{2} \mathrm{D}$ group.

The two molecular ion peaks of 3-alkyl-dodecane appeared at $\mathrm{m} / \mathrm{z} 251$ and 252 . The $\mathrm{m} / \mathrm{z} 252$ peak is assigned to the $\mathrm{C}_{6} \mathrm{D}_{5}-\mathrm{C}_{12} \mathrm{H}_{24} \mathrm{D}$ molecular ion. The cleavages of $-\mathrm{C}_{9} \mathrm{H}_{19}{ }^{+}$ and $-\mathrm{C}_{2} \mathrm{H}_{4} \mathrm{D}^{+}$from the molecular ion resulted in fragment ions of $\mathrm{m} / \mathrm{z} 125\left(\mathrm{C}_{6} \mathrm{D}_{5}-\mathrm{C}_{3} \mathrm{H}_{5} \mathrm{D}^{+}\right)$and $222\left(\mathrm{C}_{6} \mathrm{D}_{5}-\mathrm{C}_{10} \mathrm{H}_{20}{ }^{+}\right)$. Further loss of $-\mathrm{C}_{2} \mathrm{H}_{3} \mathrm{D}^{+}$and $-\mathrm{C}_{9} \mathrm{H}_{18}{ }^{+}$from the two fragment ions formed the high-abundance peak at $\mathrm{m} / \mathrm{z} 96$ which is assigned to benzyl carbonium ion $\left(\mathrm{C}_{6} \mathrm{D}_{5}-\mathrm{CH}_{2}{ }^{+}\right)$. The MS analysis showed that the 3-phenyldodecane has a linear side-chain with a $-\mathrm{C}_{2} \mathrm{H}_{4} \mathrm{D}$ group. Similar MS spectrum analysis also showed that $-\mathrm{C}_{3} \mathrm{H}_{6} \mathrm{D},-\mathrm{C}_{4} \mathrm{H}_{8} \mathrm{D}$ and $-\mathrm{C}_{5} \mathrm{H}_{10} \mathrm{D}$ groups existed in 2-, 3-phenyldodecane, and 4-, 5- and 6-phenyldodecane.

To further examine the proposed overall reaction mechanism, the ionic liquid was separated from the alkylation products of $\mathrm{C}_{6} \mathrm{D}_{6}$ with 1-dodecene and to catalyze the alkylation $\mathrm{C}_{6} \mathrm{H}_{6}$ with 1-dodecene. The result is shown in Fig. 11. 

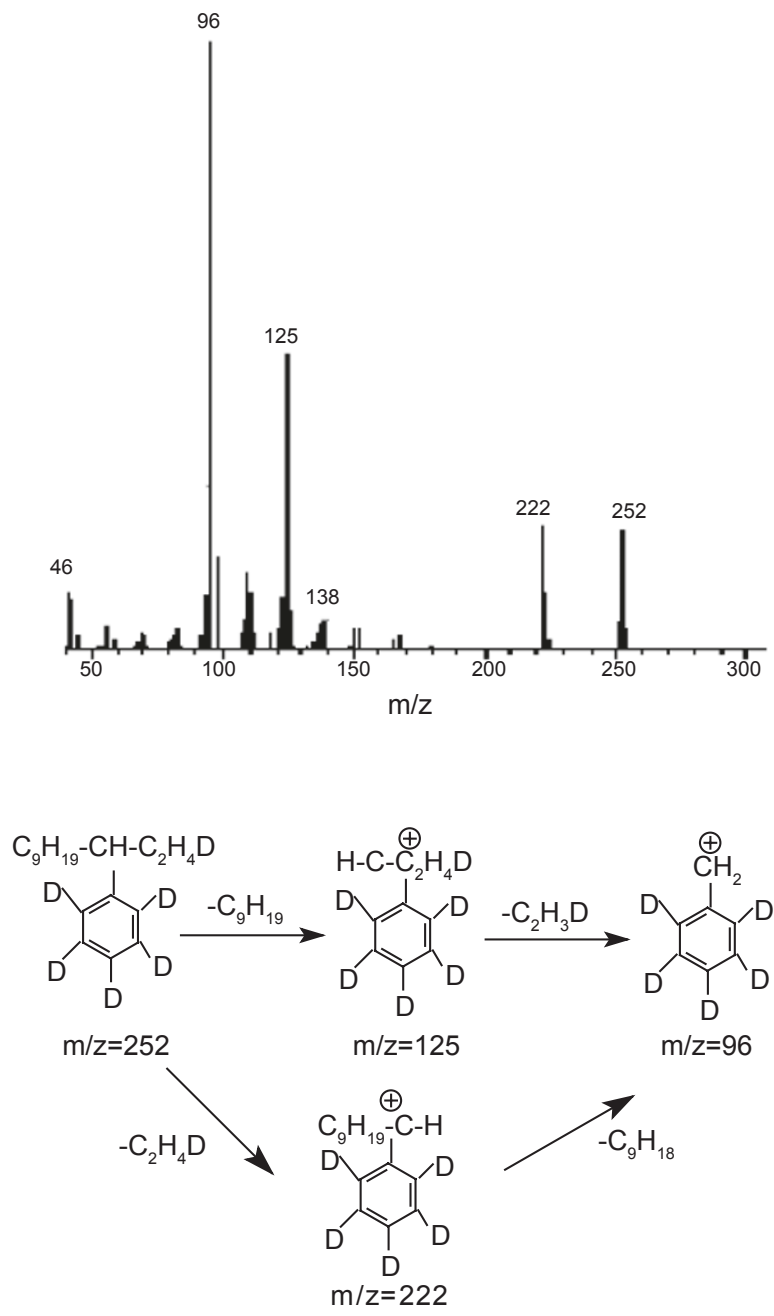

Fig. 10 Mass spectrum of 3-phenyldodecane

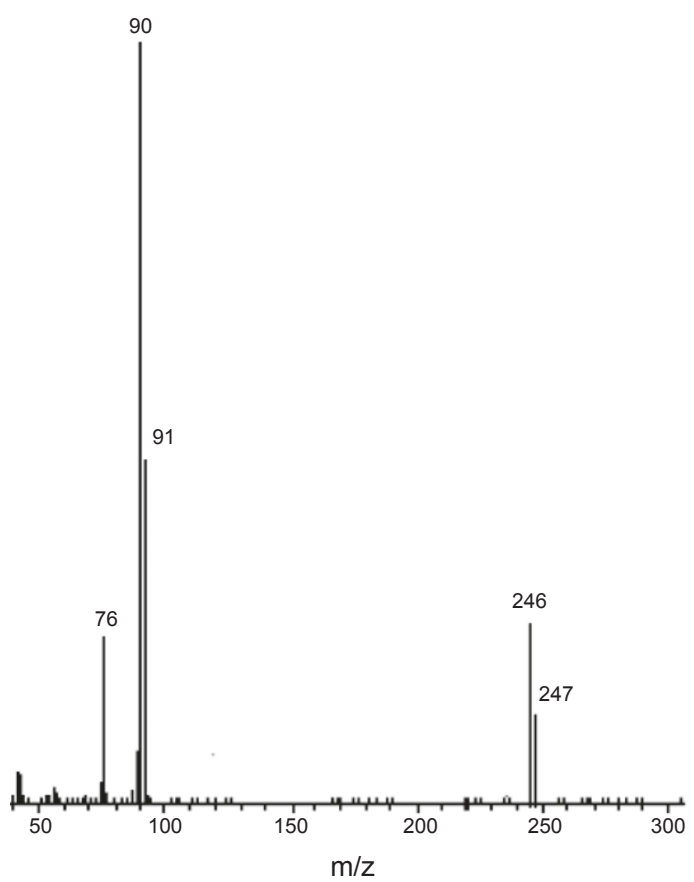

Fig. 11 MS spectrum of 2-alkyl-dodecane produced from alkylation of $\mathrm{C}_{6} \mathrm{H}_{6}$ with 1-dodecene
If the proposed mechanism was followed, carbonium ion $\left[\mathrm{AlDCl}_{3}\right]^{+}$must be the initiator in the ionic liquid at the beginning of the alkylation reactions of $\mathrm{C}_{6} \mathrm{H}_{6}$ with 1 -dodecene. The relative abundance of alkyl-dodecane at $\mathrm{m} / \mathrm{z}$ 246 must be higher than that at $\mathrm{m} / \mathrm{z} 247$. The results in Fig. 10 showed that 2- alkyl-dodecane had two peaks at m/z 246 and $\mathrm{m} / \mathrm{z} 247$ and the relative abundance of alkyl-dodecane at $\mathrm{m} / \mathrm{z}$ 246 is higher than that at $\mathrm{m} / \mathrm{z} 247$. Therefore, it is concluded that a carbocation provides the mechanism of alkylation reactions catalyzed by ionic liquid, in which the Brønsted acid $\left[\mathrm{AlHCl}_{3}\right]^{+}$is the reaction initiator, not traditional $\mathrm{H}^{+}$.

\section{Conclusions}

Based on above information, it may be concluded that the alkylation catalyzed by $\mathrm{AlC}_{3}$ ionic liquid follows a carbocation mechanism. Brønsted acid $\left[\mathrm{AlHCl}_{3}\right]^{+}$which produced by $2-\mathrm{H}$ on the imidazolium ring reacting with $\left[\mathrm{Al}_{2} \mathrm{Cl}_{7}\right]^{-}$acts as initiator instead of traditional $\mathrm{H}^{+}$. [ $\left.\mathrm{AlHCl}_{3}\right]^{+}$ reacted with dodecene first to form a carbonium ion. Then the carbonium ion further reacted with benzene to generate an unstable $\sigma$ complex, and $\mathrm{D}^{+}$on the ring of the $\sigma$ complex was transferred into ionic liquid to replace $2-\mathrm{H}$, thereby generating different dodecylbenzenes.

\section{Acknowledgement}

We are grateful for financial support from the National Natural Science Foundation of China (NSFC, 2052010). We also thank the other members of the consortium for the interesting discussions.

\section{References}

Arduengo A J, Harlow R L and Kline M A. Stable crystalline carbene. J. Am. Chem. Soc. 1991. 113(1): 361-363

Blanchard L A, Hancu D, Beckmann E J, et al. Green processing using ionic liquids and $\mathrm{CO}_{2}$. Nature. 1999. 399: 28-29

Carmichael A J, Haddleton D M, Bon S A F, et al. Copper(I) mediated living radical polymerisation in an ionic liquid. Chem. Commun. 2000. $1237-1238$

Cole A C, Jensen J L, Ntai I, et al. Novel Brønsted acidic ionic liquids and their use as dual solvent-catalysts. J. Am. Chem. Soc. 2002. 5962-5963

Compell J LE and Johnson K E. The chemistry of protons in ambienttemperature ionic liquids: solubility and electrochemical profiles of $\mathrm{HCl}$ in $\mathrm{HCl}: \mathrm{ImCl}: \mathrm{AlC1}_{3}$ ionic liquids as a function of pressure (295K). J. Am. Chem. Soc. 1995. 117: 7791-7780

Cull S G, Holbrey J D, Vargas V V, et al. Room temperature ionic liquids as replacements for organic solvents in multiphase bioprocess operations. Biotechnol. Bioeng. 2000. 69: 227-233

Decastro C, Sauvage E, Valkenberg M H, et al. Immobilised ionic liquids as Lewis acid catalysts for the alkylation of aromatic compounds with dodecene. J Catal. 2000. 196: 86-94

Gifford P R and Palmisano J B. A Substituted Imidazolium chloroaluminate molten salt possessing an increased electrochemical window. J. Electrochem. Soc. 1987. 134: 610-614

Green L, Hemeon I and Singer R D. 1-Ethyl-3-methyloimidazolium halogenoaluminate melts as reaction media. Tetrahedron Lett. 2000. 41: $1343-1345$

Hardacre C, Holbrey J D, Katdare S P, et al. Alternating copolymerisation of styrene and carbon monoxide in ionic liquids. 
Green Chem. 2002. 4: 143-146

Hope K D, Stern D A, Twomey D W, et al. Method for Manufacturing Ionic Liquid Catalysts. US 2004 0005985. 2004-01-08

Huddleston J G, Willauer H D, Swatloski R P, et al. Room temperature ionic liquids as novel media for 'clean' liquid-liquid extraction. Chem. Commun. 1998. 1765-1766

Hussey C L. Room temperature haloaluminate ionic liquids. Novel solvents for transition metal solution chemistry. Pure \& Appl. Chem. 1988. 60(12): 1763-1772

Lu Y Q and Deng Z H. Practical IR Spectrum Analysis. Beijing: Electron Industry Press. 1989 (in Chinese)

Ma M and Johnson K E. Carbocation formation by selected hydrocarbons in trimethylsulfonium bromide- $\mathrm{AlCl}_{3} / \mathrm{AlBr}_{3}-\mathrm{HBr}$ ambient temperature molten salts. J. Am. Chem. Soc. 1995. 117: 1508-1513

Munson C L, Boudreau L C and Driver S. Separation of Olefins from Paraffins using Ionic Liquid Solutions. US Patent 6339182. 200201-15

Nara S J, Harjani JR, Salunkhe M M. Friedel-crafts sulfonylation in 1-butyl-3-methylimidazolium chloroaluminate ionic liquids. J. Org. Chem. 2001. 66: 8616-8620

Qiao C Z, Zhang Y F and Li C Y. Activity and stability investigation of $[\mathrm{BMIM}]\left[\mathrm{AlCl}_{4}\right]$ ionic liquid as catalyst for alkylation of benzene with 1-dodecene. Appl. Catal. A Gen. 2004. 276: 61-66

Qiao K and Deng Y Q. Alkylations of benzene in room temperature ionic liquids modified with HCl. J. Mol. Catal. A Chem. 2001. 171: 81-84

Schmerling L. Reactions of hydrocarbons ionic mechanisms. Ind. Eng. Chem. 1953. 45: 1447-1453

Seddon K R. Ionic liquids for clean technology. J. Chem. Technol. Biotechnol. 1997. 68: 351-356

Sheldon R A, Maderia L R, Sorgedrager M J, et al. Biocatalysis in ionic liquids. Green Chem. 2002. 4: 147-151

Sherif F G, Greco C, Shyu L J, Talma A G, et al. Linear Alkylbenzene Formation using Low Temperature Ionic Liquid and Long Chain
Alkylating Agent. 1998. W0 9803454

Smith G P, Dworkin A S, Pagni R M, et al. Brønsted superacidity of $\mathrm{HCl}$ in a liquid chloroaluminate $\mathrm{A}_{1 \mathrm{C}} \mathrm{1}_{3}$-1-ethyl-3-methyl-1H-imidazolium chloride. J. Am. Chem. Soc. 1989. 111(2): 525-530

Sun X W and Zhao S Q. Alkylation mechanism of benzene with propylene catalyzed by ionic liquid under supercritical conditions. Acta Chim Sin. 2008. 66: 471-473 (in Chinese)

Swatloski R P, Spear S K, Holbrey J D, et al. Dissolution of cellulose with ionic liquid. J. Am. Chem. Soc. 2002a. 124: 4974-4975

Swatloski R P, Visser A E, Reichert W M, et al. On the solubilization of water with ethanol in hydrophobic hexafluorophosphate ionic liquids. Green Chem. 2002b. 4: 81-87

Trulove P C, Sukumaran D K, Osteryoung R A. Protons in acidic ambient-temperature chloroaluminate molten salts: Hydrogendeuterium exchange between the imidazolium cation and hydrogen chloride. J. Phys. Chem. 1994. 98: 141-146

Welton T. Room-temperature ionic liquids: Solvents for synthesis and catalysis. Chem. Rev. 1999. 99: 2071-2083

Whitmore F C. The common basis of intramolecular rearrangements. J. Am. Chem. Soc. 1932. 54: 3274

Wilkes J S, Levisky J A, Wilson R A, et al. Dialkylimidazolium chloroaluminate melts: A new class of room-temperature ionic liquids for electrochemistry, spectroscopy and synthesis. Inorg. Chem. 1982. 21: 1263-1264

Xin $\mathrm{H} \mathrm{L}$, Wu Q, Han M, et al. Alkylation of benzene with 1-dodecene in ionic liquids [Rmim] $+\mathrm{Al}_{2} \mathrm{Cl}_{6} \mathrm{X}-(\mathrm{R}=$ butyl, octyl and dodecyl; $\mathrm{X}=$ chlorine, bromine and iodine). Appl Catal A Gen. 2005. 292: 354361

Yoo K, Nambodiri V V, Varma R S, et al. Ionic liquid catalyzed alkylation of isobutane with 2-butene. J Catal. 2004. 222: 511-519

Zhao D, Wu M, Kou Y, et al. Ionic liquid: Application in catalysis. Catal. Today. 2002. 74: 157-189

(Edited by Zhu Xiuqin) 